\title{
Micro-Turbine Design, Production and Testing
}

\author{
Haci Sogukpinar ${ }^{*}$, Ismail Bozkurt ${ }^{* *}$, M. Firat Baran ${ }^{*}$, Harun Turkmenler ${ }^{* * *}$, Murat Pala ${ }^{* * * *}$, K. Emre \\ Engin $^{*}$, A. Ihsan Kaya ${ }^{*}$ \\ *Department of Energy Systems Engineering, Faculty of Technology, University of Adiyaman, Adiyaman 02040, Turkey \\ **Department of Mechanical Engineering, Faculty of Engineering, University of Adiyaman, Adiyaman 02040, Turkey \\ ****Department of Environmental Engineering, Faculty of Engineering, University of Adiyaman, Adiyaman 02040, Turkey \\ ****Department of Civil Engineering, Faculty of Engineering, University of Adiyaman, Adiyaman 02040, Turkey
}

${ }^{\ddagger}$ Corresponding Author; First Author, Department of Energy Systems Engineering, Faculty of Technology, University of Adiyaman, Adiyaman 02040, Turkey, Tel: +90 41622338 00/2840, hsogukpinar@adiyaman.edu.tr

Received: 20.11.2015 Accepted: 16.12.2015

\begin{abstract}
Large scale utilization of electricity started at the end of $19^{\text {th }}$ century with the construction first power plant and there phase current was introduced. Power plant technology evolved rapidly and electricity use has increased rapidly since then. Outbreak of energy crisis in 1970s and threat of the global warming has forced the people to search clean energy resources. Among the renewable energy sources, wind energy has become the most popular case. Development of the necessary technology for wind turbines reached a commercial competence In the 1990s. Turning to wind energy in Turkey began after 2006 and has shown a rapid increase until 2015. When considering the country's wind potential it tends to stay in rapid growth. In this study, $2 \mathrm{~kW}$ micro-turbines is designed, manufactured and tested by using local facility. The aim of this study is to design a micro-turbine for use in low wind speed area, create industrial infrastructure related to the production of micro-turbine, and develop different production technologies for local industry.
\end{abstract}

Keywords-Renewable energy, wind power, turbine design, aluminium wings.

\section{Introduction}

Use of wind energy is as old as humanity. Humanity first was used wind energy for floating vessels, grinding grain and irrigation. With the widespread use of electricity in the 20th century, new application area was born for wind power. With the energy crisis which began in 1973, searching alternative energy source has been started. Among the renewable energy sources, wind energy has become the most popular case. With this process research activities in the field of wind energy have continued to increase in the last 30 years. Development of the necessary technology for wind turbines reached a commercial competence in the 1990s. Commercial wind turbines have been started to establish since 1990 and have shown a rapid increase after 2004. Global installed capacity was around 1000 MW until 1990 but with the development of technology in this area, installed capacity doubled every three years after 1990 and total capacity increased to $60,000 \mathrm{MW}$ in 2006 [1]. According to the International Energy Agency, over the past decade terrestrial wind power installation increased $27 \%$ each year. While global setup until the end of 2000 was $18 \mathrm{GW}$, installation had been reached $238 \mathrm{GW}$ in 2011 [2]. Countries, together with the increase global warming and energy cost, have accelerated growth in this area by providing significant support to the wind energy sector.

Turning to wind energy in Turkey began after 2006 and had shown a rapid increase until 2015 [1]. When considering the country's wind potential it tends to stay in its rapid growth. Installed wind power plant in Turkey had reached nearly 4,000 MW until 2015 while global installed capacity had exceeded $350 \mathrm{GW}$. When global energy demand and costs are considered, this increase is expected to continue faster.

Although small wind turbines remain in the shade of large wind turbines, they generate appreciable electricity [2]. Micro-turbines have several advantages over large-scale turbines. The registration fee or permission is not required to establish a micro-turbine. So in recent year's very quick increase have been seen in micro-turbine installation. For example, 3715 micro turbines $(0-100 \mathrm{kw})$ installation was 
made in the UK only in 2012 [3]. Micro-turbines generally shows itself in areas where wind speeds are slow. A single turbine which scales to meet the individual needs of electricity produced from. But many small-scale turbines established in the same place, in this way production capacity was comparable to large scale turbines [4]. According to the studies, among the micro turbines, horizontal axis turbines were found to be more efficient to the vertical axis [5]. Some work based on with meteorological data, 300-1000W capacity micro-turbines were shown to meet the electricity needs of a house [6]. Micro-turbines have a wide range of uses in both rural areas and cities worldwide [7-8]. Multiple installations of micro-turbines can be integrated into the electrical grid. Emissions of greenhouse gases are reduced in this way by providing energy savings [9]. Micro-turbines are expected to have a large share of reducing greenhouse gas emissions. That's why the UK government provides incentives for the use of the micro-turbine technology [10]. 455.000-600.000 micro turbines are estimated to be installed across the UK by 2020 [11].

In this study, a micro-turbine is designed and manufactured using local industry facilities by using aluminium and steel. The main reasons for the use of these materials are that these materials can be easily processed in local industry in all around the Turkey. Blades are made from aluminium sheets $3 \mathrm{~mm}$ in thickness. The blades are attached to the $3 \mathrm{~mm}$ in thickness and $120 \mathrm{~mm}$ diameter pipe with the aid of hinges. All components except the rotor blades are made of steel. $10 \mathrm{~m}$ tower with $260 \mathrm{~mm}$ diameter is made of $10 \mathrm{~mm}$ thick steel. Foundation was previously prepared so as to screw the tower into the ground. With the help of ship ladder there is the possibility to reach nacelle safely. The prototype design will be used for training so nacelle is mounted on a platform which looks like a balcony on the tower. Gearbox, low and high speed shaft and generator are attached in the nacelle. To put the electrical and other components $2 \times 2 \times 2 \mathrm{~m}$ in size a control room is designed and manufactured. For security of people turbine is surrounded $10 \mathrm{~m}$ diameter and $2 \mathrm{~m}$ height wire mesh.

\section{Materials and methods}

According to the power capacity, wind turbines are classified as large ( $>1 \mathrm{MW})$, medium $(40 \mathrm{~kW}-1 \mathrm{MW})$ and small scale. Power generating turbines range of $0.4-2.5 \mathrm{~kW}$ is called micro turbines. Small-scale wind turbine's maximum power coefficient $\left(c_{p}\right)$ is between 0.2-0.35 [12].

The mechanical power output of the converter can be expressed with the equation (1):

$P=\frac{1}{4} \cdot A \cdot \rho \cdot\left(v_{1}^{2}-v_{2}^{2}\right)\left(v_{1}+v_{2}\right)$

Where, A is blade cross section area, $\rho$ is density of air; $v_{1}$ flow velocity in front of converter and $v_{2}$ is velocity behind the converter. The ratio between the mechanical power extracted by converter to power of airstream is defined as power coefficient $\left(c_{p}\right)$ and expressed with the equation (2) [13]:
$c_{p}=\frac{P}{P_{0}}=\frac{\frac{1}{4} \cdot A \cdot \rho \cdot\left(v_{1}^{2}-v_{2}^{2}\right)\left(v_{1}+v_{2}\right)}{\frac{1}{2} \cdot A \cdot \rho v_{1}^{3}}$

Where $\mathrm{P}_{0}$ undisturbed air stream power and $\mathrm{P}$ is extracted mechanical power by converter. After some arrangement power coefficient can be expressed with the equation (3):

$c_{p}=\frac{P}{P_{0}}=\frac{1}{2}\left[1-\left(\frac{v_{2}}{v_{1}}\right)^{2}\right]\left[1+\frac{v_{2}}{v_{1}}\right]$

The power coefficient directly depends on the ratio of air velocities as shown in equation (3). With the speed ratio $1 / 3$, the maximum power coefficient $\left(c_{p}\right)$ can be obtained as 0.593. Betz was the first to derive this value, therefore frequently called the Betz factor. According to the some simplifications the maximum power generated at the turbine is calculated with the help of equation (4):

$P=\frac{1}{2} \cdot c_{p} A \cdot \rho_{a} \cdot v^{3}$

Max amount of power to be generated in a turbine is directly proportional to the third power of the wind speed, so setting up the wind turbines in places where high wind speeds is always more advantageous. Doubling the wind speed rises to eight times the amount of power produced. So large-scale wind turbines are installed at a place where the wind speed is high. However, low windy places where establishing micro turbines can be offered to individual use.

Momentum theory by Betz indicates theoretical maximum power limit. But in realty power coefficient depends on characteristics of energy converter. Aerodynamic lift and drag are the most effective on power therefore, utilization of aerodynamic lift increase the efficiency. The lift force is due to the difference in airflow speed (pressure difference) between the top and bottom of the blades. Aerodynamic forces acting on airfoil S822 is simulated and shown in Figure 1. This airfoil is used for small scale wind turbine blade production with the rotor diameter between 3 and $10 \mathrm{~m}$. As shown in Figure 1 at the bottom of the airfoil there is high pressure but in the upper part of the airfoil comprises low pressure. The pressure difference between the top and bottom of airfoil creates a lift force in the upward direction.

In this study, the blades are made from aluminium sheets and pipes. Aluminium plate is cut into shape of the blades and screwed to aluminium pipe to form rotor. Blades design and the parameters are given in Figure 2. The blades are rotated to the wind speed direction with the angle of attack 30 degrees and fixed to the rotor hub. Mechanical energy is transmitted from rotor to low speed shaft which is connected to gear box. Rotation increased 8 times in gear box and mechanical energy transfer to high speed shaft which is connected to alternator to generate electricity. Working diagram of mechanical component is shown in Figure 3. 


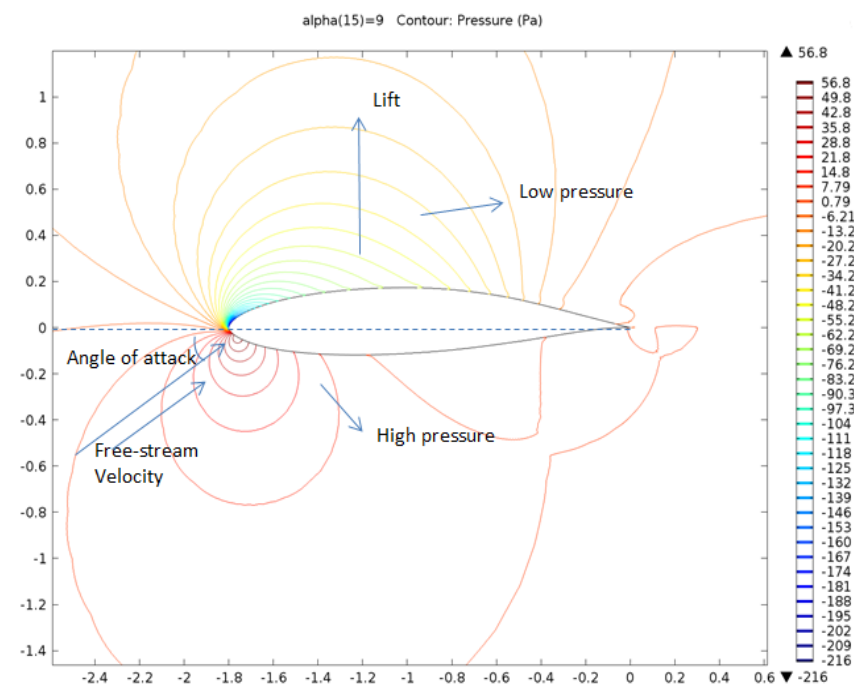

Fig. 1. Pressure contours for S822 airfoil at the angle of attack $9^{\circ}$ and $10 \mathrm{~m} / \mathrm{s}$

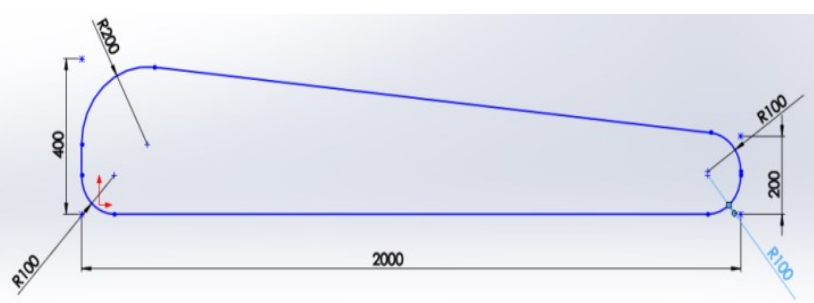

Fig. 2. CAD design of blades and parameters

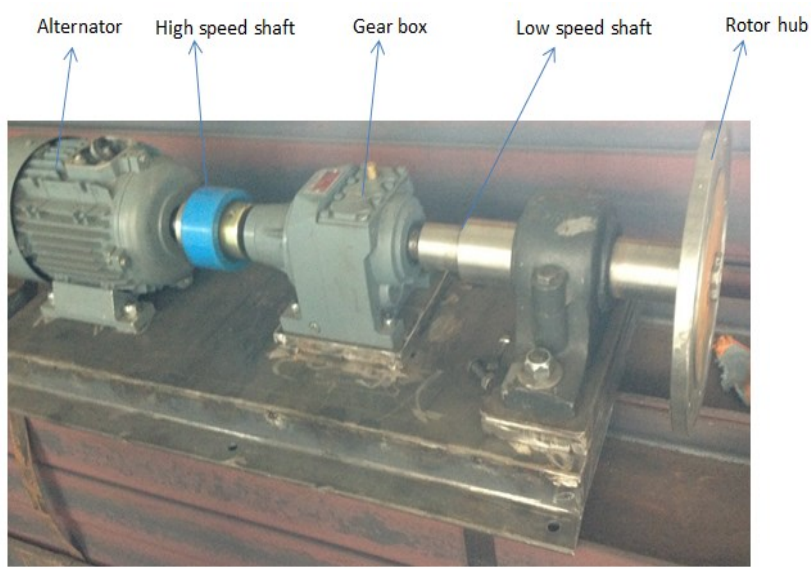

Fig. 3. Working diagram of the mechanical component

Setup diagram of the system is given in Figure 4. Generated electricity is transferred to the control unit before charging. The control unit makes the control of the battery charging and also used to stop the turbine when the battery is full. To use electricity when there is no wind it is stored in the battery. Two 150 A gel batteries are used to store 3.6 $\mathrm{kWh}$ in this test run.

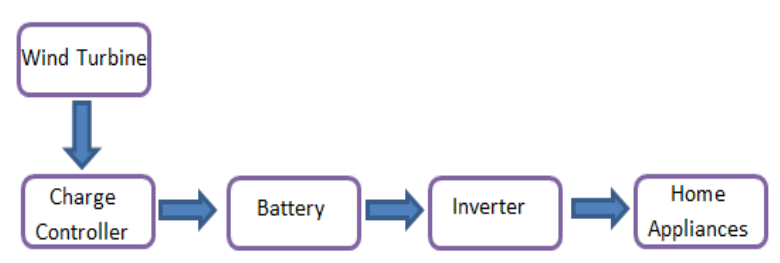

Fig. 4. Set up diagram of the system

In previous experimental studies indicates that microturbine power coefficient ranged between 0.2 and 0.35 . Wind turbine is designed for a place for a low wind speed area therefore, blade diameter is larger than the power of the alternator. In this way, turbine is able to produce electricity at low wind speed. With respect to calculations, when the wind speed is $5 \mathrm{~m} / \mathrm{s}$ it has production capacity of $0.5 \mathrm{~kW}$. When the wind speed increased to $7 \mathrm{~m} / \mathrm{s}$, production capacity reaches $1.4 \mathrm{~kW}$, finally with the speed of $9-10 \mathrm{~m} / \mathrm{s}$ capacity becomes $100 \%$.

\section{Results and Discussion}

Because Turkey is surrounded by sea on three sides and inner geographic differences make it rich in the presence of different climatic wind. Wind map is shown in Figure 5 and Marmara, Aegean, Black Sea and the Mediterranean region coast is comprised of high energy winds value. According to the wind speed distribution Turkey wind potential is presented in Table 1 .

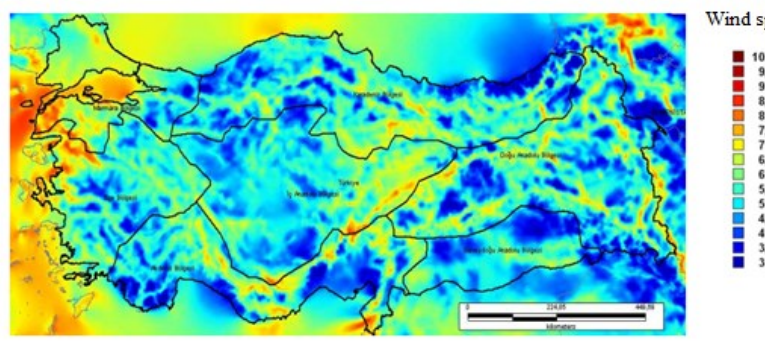

Fig. 5. Wind map of Turkey [14]

Table 1. Wind energy potential in Turkey [14]

\begin{tabular}{|l|l|l|}
\hline $\begin{array}{l}\text { Annual } \\
\text { Average Wind } \\
\text { Speed (m/s) }\end{array}$ & $\begin{array}{l}\text { Average Wind } \\
\text { Power Density } \\
\mathbf{W} / \mathbf{m}^{2}\end{array}$ & $\begin{array}{l}\text { Total installable } \\
\text { power (MW) }\end{array}$ \\
\hline $7.0-7.5$ & $400-500$ & $29,259.36$ \\
\hline $7.5-8.0$ & $500-600$ & $12,994.32$ \\
\hline $8.0-9.0$ & $600-800$ & $5,399.92$ \\
\hline$>9.0$ & $>800$ & 195.84 \\
\hline \multicolumn{2}{|l}{ Total } & $\mathbf{4 7 , 8 4 9 . 0 0}$ \\
\hline
\end{tabular}

Total assessable wind energy potential is calculated as 47,849 MW around the Turkey for over $7 \mathrm{~m} / \mathrm{s}$. This is the economic potential for large wind turbines installation. Also total wind power potential is calculated as 83,900 MW for wind speed in the range of $6,5-7 \mathrm{~m} / \mathrm{s}$. This range is consistent 
for small scale wind turbines. For this range Turkey has very high wind potential so micro-turbine installation is great importance for Turkey. Given that total installed power capacity of Turkey was $60,000 \mathrm{MW}$ by $201484.000 \mathrm{MW}$ is more than scale to meet the needs of potential of the country. Total electricity consumption in Turkey was 198,045,181 MWh and $22.7 \%$ of it was consumed in the house in 2014. Any permit is not required for the installation of individual small scale wind turbines. If only spreading the use of small wind turbines for homes, large-scale contribution to the national economy can be provided. Because amount of electricity produced from natural gas constitute $43.6 \%$ of the total production. Almost all of the natural gas consumed for generating electricity is imported. Another aspect, each passing day global warming reaches with threats in size and requires alternative solutions. By encouraging the use of small wind turbines in national and international level, remarkable scale carbon dioxide emissions can be reduced.

In this study, a micro-turbine is designed and manufactured using local industry facilities by using aluminum and steel. The main reasons for the use of these materials that these materials can be easily processed in local industry in all around the Turkey. Blades are made from aluminum sheets $3 \mathrm{~mm}$ in thickness. The blades are attached to the $3 \mathrm{~mm}$ in thickness and $120 \mathrm{~mm}$ diameter pipe with the aid of hinges. All components except the rotor blades are made of steel. $10 \mathrm{~m}$ tower with $260 \mathrm{~mm}$ diameter is made of $10 \mathrm{~mm}$ thick steel. Foundation was previously prepared so as to screw the tower into the ground. With the help of ship ladder there is the possibility to reach nacelle safely. The prototype design will be used for training so nacelle is mounted on a platform which looks like a balcony on the tower. Gearbox, low and high speed shaft and generator are attached in the nacelle. To put the electrical and other components $2 \times 2 \times 2 \mathrm{~m}$ in size a control room is designed and manufactured. For security of people turbine is surrounded $10 \mathrm{~m}$ diameter and $2 \mathrm{~m}$ height wire mesh.

Mechanical energy generated in the rotor is transferred to gearbox via low speed shaft. After rotation is increased eight times in gearbox, mechanical energy is transferred to the high-speed shaft. Generator is a $2 \mathrm{~kW}$ alternator type of machine that can generate electricity. When the speed of rotation reaches $200 \mathrm{rpm}$, power generation starts. Electricity produced in the generator is initially stored in two $200 \mathrm{~A}$ gel batteries. With the help of an inverter, electric current from the battery is converted to $220 \mathrm{~V}$ ac before use. When the battery is fully charged control unit stops the movement of rotor by stimulating the magnetic brake system in the generator. Likewise, when the wind blows very fast the magnetic brake system comes into play again. Yaw mechanism is controlled automatically by the wind. The materials used in this study are planned by considering the possibilities of the domestic industry. This wind turbine is designed and constructed for the places where wind speed is less than $7 \mathrm{~m} / \mathrm{s}$ and complete design is shown in Figure 6 . Wind turbine is builted in Adiyaman University Campus.

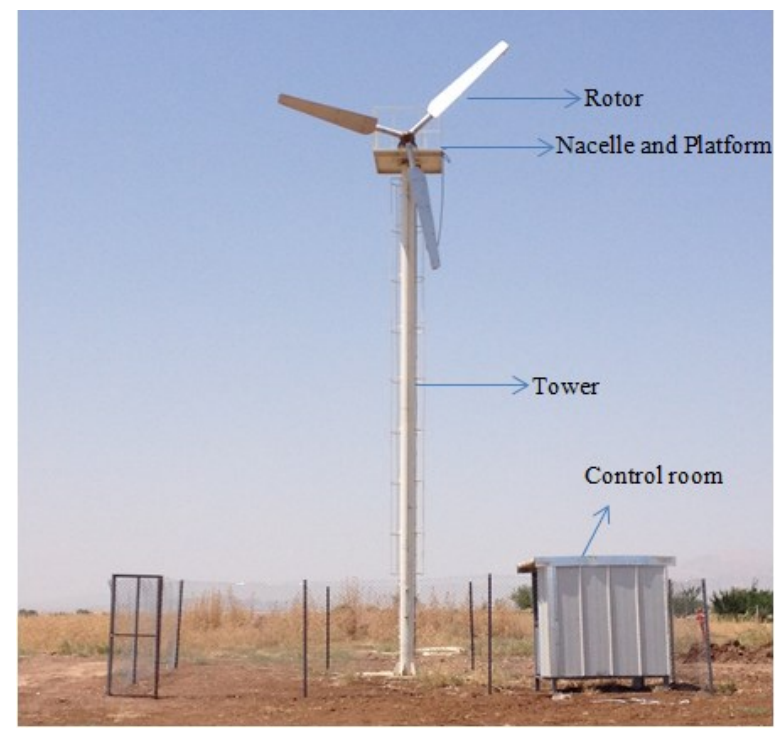

Fig. 6. Wind turbine

\section{Conclusion}

$85 \%$ portion of the electrical energy produced today is derived from fossil fuels. Because of the limited oil, natural gas and coal reserves in the world and threat of global warming are mandatory to find alternative energy sources. In addition, energy prices in today world cost very high amount. Without the resources to produce its own energy, states are spending serious upheaval in financial terms. Use of fossil fuels is releasing greenhouse gases it is causing global warming. Reduction of greenhouse gases for a better world has now become a necessity. Wind energy has significant potential in this respect. Wind turbine technology has completed the necessary infrastructure for installation. Turkey has very high wind potential in the range between $6.5-7 \mathrm{~m} / \mathrm{s}$ according to its consumption so making widespread of small-scale wind turbines are great importance. Domestic production of wind turbine should be supported. By encouraging small-scale wind turbines can increase the use of clean energy, could contribute the country's economy, gives opportunity to leave a cleaner country for the new generation, pay less money for energy import and can contribute to the economy by making domestic production. The way to turn off the energy sourced foreign trade deficit recover with the production of domestic resources with indigenous technology. Otherwise, the wind turbines bought from abroad is a serious cost

In this study $5 \mathrm{~m}$ in diameter turbine rotor is designed and manufactured entirely using local facilities and materials. The blades are made of aluminium sheet and pipe, other parts of system are manufactured from steel. Control unit, gearbox, gel batteries, inverter and alternator are provided by the way of purchasing from the national manufacturer. This study has taken into consideration the infrastructure of the domestic industry. 


\section{Funding}

This work was supported by Adiyaman University Scientific Research Project (project no: TFBAP/2014-0003).

\section{Acknowledgment}

I thank Middle East Technical University, allowing me to this work in there with their facility.

\section{References}

[1] IEA, Energy technology perspectives 2012, pathways to a clean energy system. OECD Publishing. pp. 690, 2012.

[2] H. Sogukpinar, I. Bozkurt, "Wind energy utilization, potential and targets after 2013 in Turkey, Europe and the world", Adıyaman Üniversitesi Mühendislik Bilimleri Dergisi, Vol. 1 pp. 23-30, 2014.

[3] A. Pourrajabian, R. Ebrahimi, M. Mirzaei, "Applying micro scales of horizontal axis wind turbines for operation in low wind speed regions", Energy Conversion and Management, Vol. 87 pp. 119-127, 2014. [4] J.D.K. Bishop, G.A.J. Amaratunga, "Evaluation of small wind turbines in distributed arrangement as sustainable wind energy option for Barbados", Energy Conversion and Management, Vol.49, pp.1652-61, 2008.

[4] L.M. Al-Hadhrami, "A performance evaluation of small wind turbines for off grid applications in Saudi Arabia", Energy Conversion Management, Vol. 81, pp.19-29. 2014.

[5] A. Mostafaeipour, "Economic evaluation of small wind turbine utilization in Kerman, Iran", Energy Conversion Management, Vol. 73, pp.14-25. 2013.
[6] A.S. Bahaj, L. Myers, P.A.B. James, "Urban energy generation: influence of micro-wind turbine output on electricity consumption in buildings", Energy Buildings, Vol. 39, pp.154-65, 2007.

[7] A. Gagliano, F. Nocera, F. Patania, A. Capizzi, "Assessment of micro-wind turbines performance in the urban environments: an aided methodology through geographical information systems", Int J Energy Environ Eng, Vol. 4(1) pp. 1-14, 2013.

[8] M. Motevasel, A.R. Seifi, "Expert energy management of a micro-grid considering wind energy uncertainty", Energy Convers Manage, Vol.83, 58-72, 2014.

[9] Ofgem, "Introducing the feed-in tariff scheme in London”: Available at: www.ofgem.gov.uk 2011.

[10] BWEA. "Small wind systems". UK market report. Available at www.ecobuild.co.uk. 2009.

[11] K.Ronit, M. Singh, A. Rafiuddin, "Blade design and performance testing of a small wind turbine rotor for low wind speed applications", Renewable Energy, Vol.50, pp. 812-819, 2013.

[12] H. Erich, "Wind turbine". Springer.2013. ISBN 978-3642-27150-2.

[13] C. Mustafa, "Rüzgâr Enerjisi ve Santralleri Semineri", Rahmi Koc Museum Conference Hall - Istanbul. Available at:<http:// http://www.tucsa.org.tr/>, 2011.M. Balat, "The use of renewable energy sources for energy in Turkey and potential trends", Energy Explor Exploit, 22: 241-57, 2004. 